\title{
Screening of High Temperature-Tolerant Oleaginous Diatoms
}

\author{
Lingxiang Zhang ${ }^{1,3}$, Fan $\mathrm{Hu}^{2}$, Xiu Wan', Yufang Pan', and Hanhua Hu${ }^{1 *}$ \\ ${ }^{1}$ Key Laboratory of Algal Biology, Institute of Hydrobiology, Chinese Academy of Sciences, Wuhan 430072, P.R. China \\ ${ }^{2}$ School of Foreign Languages, China University of Geosciences, Wuhan 430074, P.R. China \\ ${ }^{3}$ University of Chinese Academy of Sciences, Beijing 100049, P.R. China
}

\begin{abstract}
Screening suitable strains with high temperature adaptability is of great importance for reducing the cost of temperature control in microalgae cultivation, especially in summer. To obtain high temperature-tolerant diatoms, water samples were collected in summer from 7 different regions of China across the Northeast, North and East. A total of 731 water samples was collected and from them 131 diatom strains were isolated and identified based on the 18S rRNA sequences. Forty-nine strains out of the 131 diatoms could survive at $30^{\circ} \mathrm{C}$, and 6 strains with relatively high biomass and lipid content at high temperature were selected and were found to be able to grow at $35^{\circ} \mathrm{C}$. Cyclotella sp. HB162 had the highest dry biomass of $0.46 \mathrm{~g} / \mathrm{l}$ and relatively high triacylglycerol (TAG) content of $237.4 \mathrm{mg} / \mathrm{g}$ dry biomass. The highest TAG content of $246.4 \mathrm{mg} / \mathrm{g}$ dry biomass was obtained in Fistulifera sp. HB236, while Nitzschia palea HB170 had high dry biomass ( $0.33 \mathrm{~g} / \mathrm{l})$ but relatively low TAG content ( $105.9 \mathrm{mg} / \mathrm{g}$ dry biomass). N. palea HB170 and Fistulifera sp. HB236 presented relatively stable growth rates and lipid yields under fluctuating temperatures ranging from 28 to $35^{\circ} \mathrm{C}$, while Cyclotella HB162 maintained high lipid yield at temperatures below $25^{\circ} \mathrm{C}$. The percentage of saturated fatty acids and monounsaturated fatty acids in all the 6 strains was $84-91 \%$ in total lipids and $\mathbf{9 0 - 9 4 \% ~ i n ~ T A G s , ~ w h i c h ~ m a k e s ~ t h e m ~ t h e ~ i d e a l ~ f e e d s t o c k ~ f o r ~ b i o d i e s e l . ~}$
\end{abstract}

Keywords: Diatom, high temperature, triacylglycerol, fatty acids, lipid production

Received: February 27, 2020 Accepted: April 20, 2020

First published online: April 23, 2020

*Corresponding author Phone: $+86-27-68780078$ Fax: +86-27-68780078 E-mail: hanhuahu@ihb.ac.cn

Supplementary data for this paper are available on-line only at http://jmb.or.kr.

pISSN 1017-7825 elSSN 1738-8872

Copyright(C) 2020 by The Korean Society for Microbiology and Biotechnology

\section{Introduction}

With the exhaustion of fossil fuels and the aggravation of environmental problems from fossil fuels usage, renewable and environmentally friendly energy sources are being explored [1]. Biodiesel, referred to as fatty acid methyl esters (FAMEs) and fatty acid ethyl esters, is recognized as an ideal substitute for fossil fuels to solve the energy crisis [2]. Conventional biodiesel is mainly produced from vegetable oils or animal fats [3]. Nevertheless, the large-scale production of biodiesel from them adversely impacted supplies of food and other agricultural products, leading to an increase in the price of biodiesel and impeding its usage [3, 4]. Microalgae, as the most promising feedstock for biodiesel production, have attracted considerable attention [5]. The main attractions of using microalgae for biodiesel production are the short growth cycle, high biomass and lipid content, less occupied land, easier cultivation and ease of being modified by biotechnological means [5-7].

Screening high quality microalgae and determining the microalgae oil production efficiency are the basis and core of microalgae energy development [8]. Until now, many algal species have been selected as potential feedstock for mass biodiesel production, such as industrial oleaginous Nannochloropsis spp., Chlorella species including Chlorella protothecoides and Chlorella vulgaris, diatoms Cyclotella cryptica and Phaeodactylum tricornutum, and so on [9-13]. Diatoms have been regarded as competent strains for biofuel production due to their superiorities, including rapid multiplication, short life spans, and higher productivity ecologically than other algal classes [14]. They are at least on a par with, if not superior to, other classes of algae in terms of their ability to accumulate lipids, and they can rapidly induce triacylglycerol (TAG) accumulation under Si limitation [14]. Diatoms, responsible for about $20 \%$ of the primary production on Earth, are not only widely distributed but also highly diverse with an estimation of over 100,000 species [15].

Growth rate, lipid productivity and fatty acid composition of diatoms are influenced tremendously by temperatures, thus temperature adaptation is of great importance for screening strains to ensure high lipid productivity [16]. Diatoms usually thrive in cold seasons and are not suitable for outdoor mass cultivation in hot seasons. With increasing temperature, the proportions of saturated fatty acids (SAFA) and monounsaturated fatty acids (MUFA) have increased significantly in some microalgae [17], and ideal strains should contain high relative percentages of SAFA and MUFA for production of high-quality biodiesel $[18,19]$. Therefore, the ability of diatoms to tolerate high temperatures must be taken into account in the screening process, especially in an outdoor mass cultivation $[20,21]$. 
In this study, diatom strains isolated from freshwater in seven provinces of China were screened by thin-layer chromatography (TLC) for a rough identification of high lipid productive strains on the basis of the relative TAG content. High oleaginous diatoms with high temperature tolerance were cultivated at different temperatures. Their growth, total lipid and TAG contents, and fatty acid compositions were evaluated to obtain good diatom strains with inherent tolerance to high or fluctuating temperatures. Three diatom strains, Cyclotella sp. HB162, Fistulifera sp. HB236 and Nitzschia palea HB170, showed good adaptation to high or fluctuating temperatures and could serve as potential feedstock for outdoor biodiesel production.

\section{Materials and Methods}

\section{Sampling and Isolation}

Water samples were collected in summer (mainly from June to September) from reservoirs, rivers, lakes and ponds in the provinces of Liaoning (LN), Jilin (JL), Zhejiang (ZJ), Heilongjiang (HLJ), Hebei (HB), Shanxi (SX) and the Inner Mongolia Autonomous Region (NM) of China. The location, $\mathrm{pH}$, temperature and electrical conductivity of the water bodies were recorded (supplementary data). Algal colonies were isolated from the water samples with CSi medium [22] agar (1.2\%) using the spread plate method as described before [21]. Individual colonies were then picked and further purified by repeated streaking on a new plate. Subsequently, these purified unialgal forms were maintained by frequent sub-culturing in CSi medium at $22^{\circ} \mathrm{C}$ under $30 \mu \mathrm{mol} \mathrm{photons} /\left(\mathrm{m}^{2} \mathrm{~s}\right)$ continuous illumination before use.

\section{Identification of Diatoms}

All isolated microalgae strains were initially examined by microscopy and those diatom strains were then identified by $18 \mathrm{~S}$ rRNA sequence analysis. Total genomic DNA of the diatom strains was extracted according to the manufacturer's instructions for a glass milk DNA isolation kit (Fermentas, Lithuania). The 18S rRNA gene amplification was carried out, using the general primers 18S-1 (5'-tggttgatcctgccagtagtc-3') and 18S-2 (5'tgatccttctgcaggttcacc-3'), by polymerase chain reaction (PCR) as previously described [23]. Agarose gel purification of PCR product was carried out using the Aid Quick Gel Extraction Kit (Aidlab Biotech, China). Then, purified product was cloned into pMD18-T (Takara, China) and sequenced. Sequencing results were aligned using the NCBI Nucleotide BLAST. Phylogenetic analyses were performed by PAUP4.0b [24], with 1000 bootstrap replicates for neighbor-joining and parsimony analyses and with 100 replicates for the maximumlikelihood analysis using Ulothrix zonata (Z47999) and Gloeotilopsis planctonica (Z28970) as the outgroup.

\section{Preliminary Screening of High Oleaginous Diatoms}

All diatom strains were grown in $50 \mathrm{ml}$ flasks containing $20 \mathrm{mlCSi}$ liquid medium (the starting density is $2 \times 10^{5}$ cells $/ \mathrm{ml})$ at $22^{\circ} \mathrm{C}$ under continuous illumination of $50 \mu \mathrm{mol}$ photons $/\left(\mathrm{m}^{2} \mathrm{~s}\right)$ for $15 \mathrm{~d}$, then total lipids were extracted from the cell pellets and analyzed using TLC for the comparison of the TAG content. TLC was performed as described by Reiser and Somerville [25] on silica gel plates 60 F254 (Merck KgaA, Germany). Triolein (Sigma, USA) was used as the standard for qualitative analysis of TAGs, and the relative quantity of TAGs was evaluated using ImageJ software based on the gray intensity. Total lipids were extracted according to the procedure described by Bligh and Dyer [26] and their contents were determined with gravimetric method. Briefly, the lipids were extracted with chloroform-methanol $(1: 1, \mathrm{v} / \mathrm{v})$ from $100 \mathrm{mg}$ dry cells and separated into chloroform and aqueous methanol layers by centrifugation. Lipid phase was pipetted to a new tube for evaporation under a gentle stream of nitrogen. The evaporated residue was dried in an oven at $105^{\circ} \mathrm{C}$ for hours to a constant weight, and then the total lipid contents were determined by the weight method.

\section{Screening High Temperature Tolerant Diatoms}

For preliminary screening of high temperature-tolerant diatom, all strains were grown at $30^{\circ} \mathrm{C}$ with the starting density of $2 \times 10^{5}$ cells $/ \mathrm{ml}$ for 15 days, and then cell survival was detected by both naked eye and microscope observation. Subsequently, all 49 surviving strains were cultivated in glass tubes $(3 \mathrm{~cm}$ of inner diameter and $35 \mathrm{~cm}$ of height) at $28^{\circ} \mathrm{C}$ for 10 days. Cell density and size were determined under microscope using a Malassez chamber $(0.2 \mathrm{~mm})$. For comparison, relative cell biomass was obtained based on cell density and cell area, and the relative lipid yield was calculated from relative cell biomass and the total lipid content was measured as above.

\section{Growth of 6 Representative Diatom Strains}

Six diatom strains (Cyclotella sp. HB162, Fistulifera sp. HB236, Nitzschia palea HB170, Nitzschia sp. ZJ183, Nitzschia sp. ZJ184 and Nitzschia sp. HLJ48) were selected and cultivated in glass culture tubes containing $180 \mathrm{ml}$ of CSi medium with aeration by sterile air under continuous illumination of $70 \mu \mathrm{mol}$ photons $/\left(\mathrm{m}^{2} \mathrm{~s}\right)$ at different temperatures for 10 days. Cell density was determined by cell counts using the Malassez chamber every 2 days and specific growth rates $(\mu)$ were calculated according to $\mu=\left(\ln X_{t}-\ln X_{0}\right) / t$, where $X_{0}$ is the initial cell density and $X_{t}$ is the cell density after $t$ days. Algal dry biomass was determined by the weight method at the end of the experiment.

\section{Total Lipid and TAG Contents of 6 Representative Diatom Strains}

Total lipids of six representative diatom strains from 22,25 , and $28^{\circ} \mathrm{C}$ cultures were extracted and their contents were determined by weight method. The total lipids from $25^{\circ} \mathrm{C}$ cultures were resolved by TLC, and TAGs were scraped out and methylated with sulfuric acid-methanol. TAG contents were determined based on all fatty acid methyl ester peak areas using gas chromatography, and methyl heptadecanoic acid (C17:0) was used as an internal standard. 


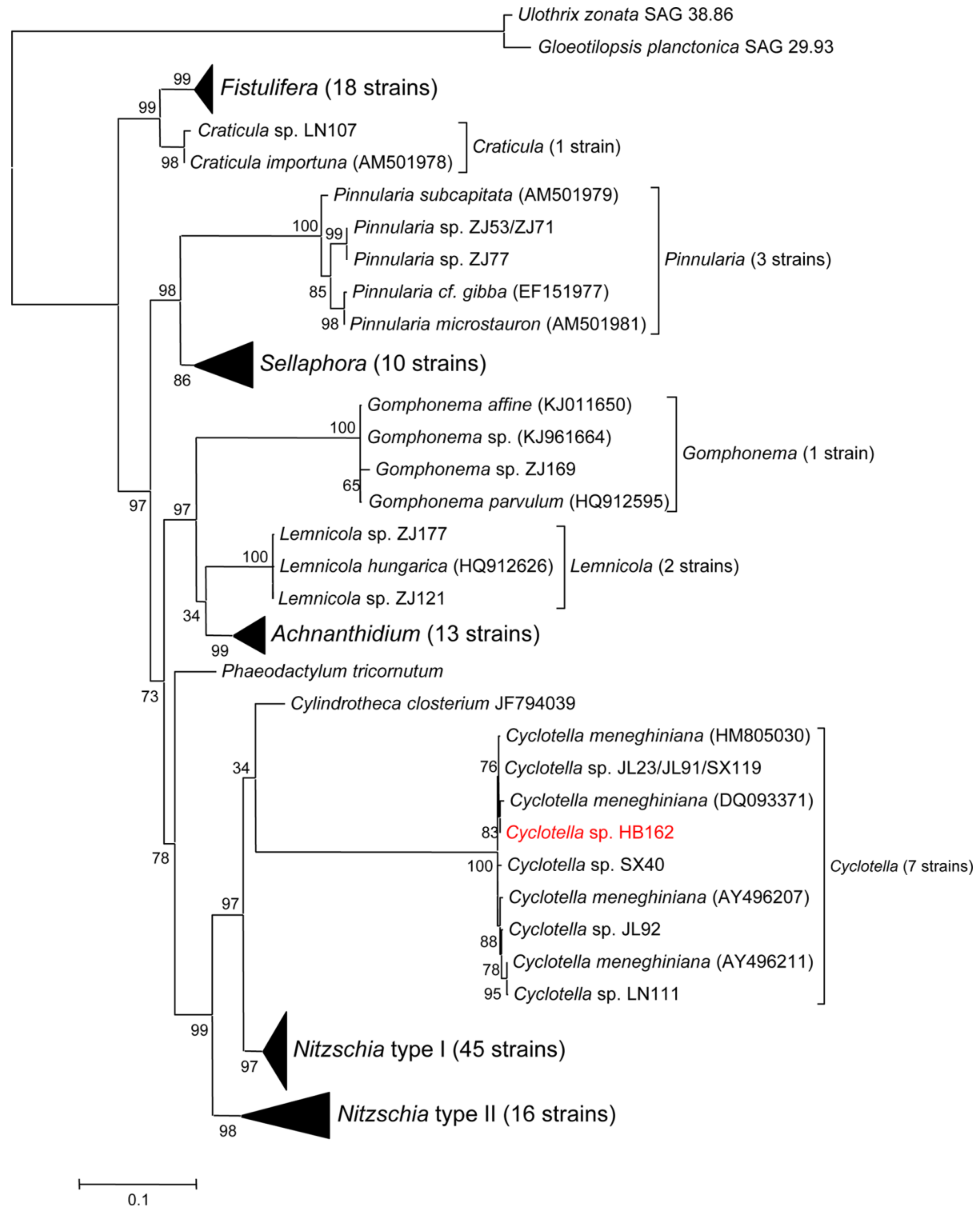

Fig. 1. A maximum-likelihood tree based on $18 S$ rRNA gene sequences illustrating the phylogeny of the isolated diatoms. Branch lengths correspond to the evolutionary distances. A distance of 0.1 is indicated by the scale. The selected strain for detailed study is in red.

\section{Fatty Acid Composition of Total Lipid and TAG}

Total lipids of 6 representative diatom strains from $25^{\circ} \mathrm{C}$ cultures were obtained as described above. TAGs were separated by TLC and the band of TAGs on the plates was scraped out and then extracted with chloroform. Total lipids and TAGs were methylated with sulfuric acid-methanol as described before [23]. Gas chromatography of the FAMEs was carried out with a TRACE GC (Thermo Scientific, Italy) equipped with a flame ionization detector, a capillary column $(60 \mathrm{~m} \times 0.25 \mathrm{~mm})(\mathrm{DB}-23$, J\&W Scientific, USA) and a split/splitless injector. Highly purified $\mathrm{N}_{2}$ gas was used as the carrier gas with a flow rate of $2.0 \mathrm{ml} / \mathrm{min}$. Initial column temperature was set at $50^{\circ} \mathrm{C}$ and subsequently raised to $170^{\circ} \mathrm{C}$ at $40^{\circ} \mathrm{C} / \mathrm{min}$, then raised to $210^{\circ} \mathrm{C}$ at $18^{\circ} \mathrm{C} / \mathrm{min}$ and held for $28 \mathrm{~min}$. Two microliters of sample were injected into the inlet and FAMEs were identified by chromatographic comparison of their retention time with authentic standards (Sigma). Heptadecanoic acid (C17:0) was used as internal standard. The quantity of individual fatty acids was calculated based on the peak area of a fatty acid species to the total peak area of all the fatty acids in the sample.

\section{Results and Discussion}

\section{Isolation and Identification of Diatoms}

Diatoms are widely distributed in freshwater, and are remarkably dominant species in the cold season during winter and early spring [27]. Therefore, in order to obtain high temperature-tolerant diatoms, water samples were 
A

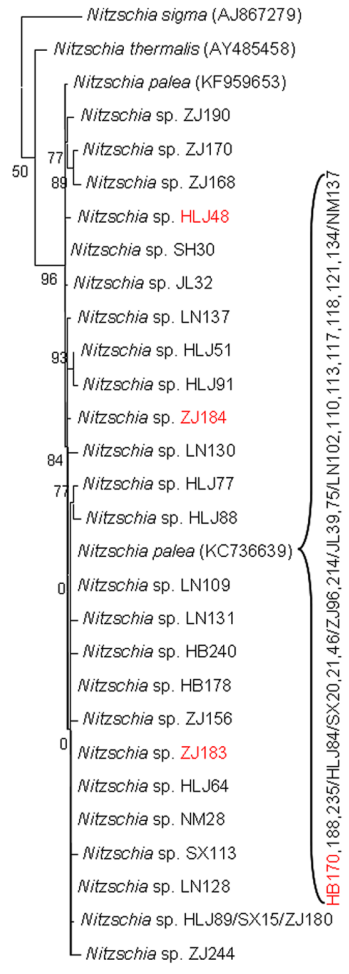

B

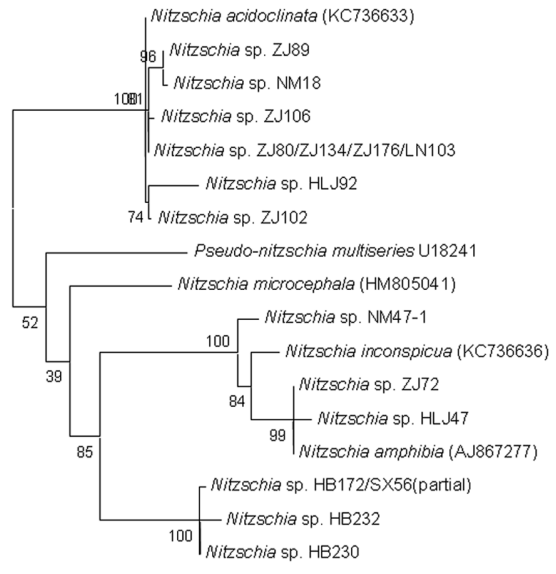

D

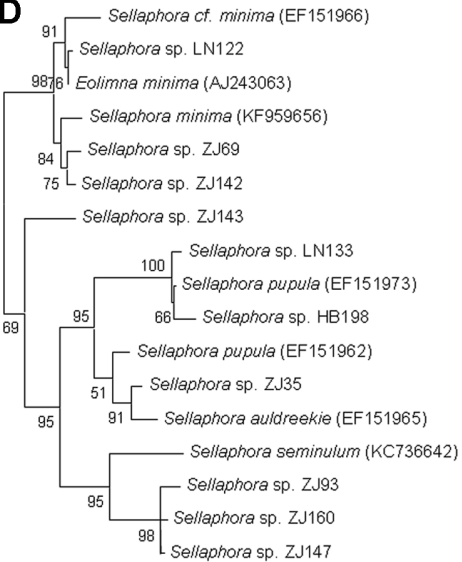

C

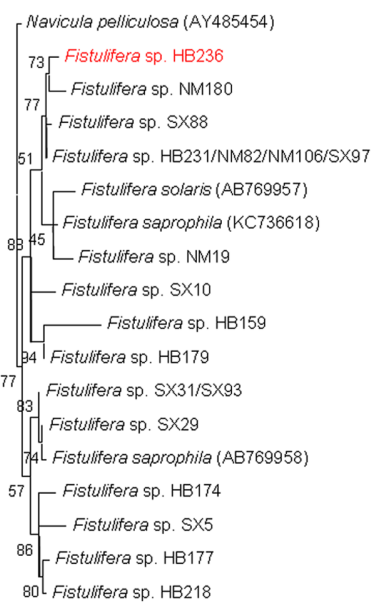

E

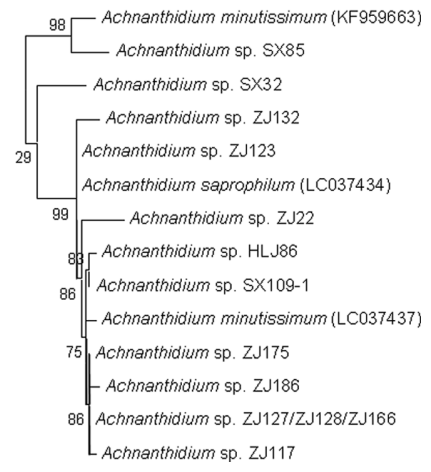

Fig. 2. The maximum-likelihood subtree from Fig. 1 showing all isolated strains in genera Nitzschia (A and B), Fistulifera (C), Sellaphora (D), and Achnanthidium (E). The selected strains for detailed study are in red.

collected in summer from 7 different regions of China across the Northeast, North and East. A total of 731 water samples was collected and from them 131 diatom strains were isolated. Except for 5 unidentified species, 13 strains were from Achnanthidium, 1 from Craticula, 7 from Cyclotella, 23 from Fistulifera, 1 from Gomphonema, 2 from Lemnicola, 65 from Nitzschia, 3 from Pinnularia, 10 from Sellaphora and 1 from Synedra based on the morphological characteristics and $18 \mathrm{~S}$ rRNA gene sequence analysis.

Phylogenetic trees of our isolated diatoms with known diatom species provided a clear resolution to generic assignment (Fig. 1). Nine genera formed 10 clades. Genus Nitzschia was divided into two monophyletic groups, which is consistent with the previous report of Lundholm, et al. [28]. One group contained Nitzschia sigma, $N$. thermalis, N. palea and isolated strains HLJ48, ZJ183, ZJ184, HB170, and etc. (Fig. 2A). The other one contained Pseudo-Nitzschia multiseries (Fig. 2B), and Pseudo-Nitzschia has been recognized as a genus distinct from Nitzschia [29]. Nineteen isolated Nitzschia strains, including HB170, HLJ84, SX20, ZJ96, JL39, LN102, and NM137, were found to be identical to $N$. palea in $18 S$ rRNA sequence. The $18 S$ rRNA gene of Fistulifera sp. HB236 had $99.3 \%$ sequence similarity to that of Fistulifera solaris (Fig. 2C), an excellent oleaginous diatom [30]. Cyclotella sp. HB162 clustered together with 4 Cyclotella meneghiniana strains, and shared an 18S rRNA gene sequence similarity of $99.8 \%$ with C. meneghiniana HM505030 (Fig. 1).

\section{Habitats, Total Lipids and TAGs of Isolated Diatoms}

Among the 131 diatom strains, 39 were isolated from the Northeast (Liaoning, Jilin, and Heilongjiang Provinces), 51 from the North (Hebei and Shanxi Provinces, and Inner Mongolia Autonomous Region) and 41 from the East (Zhejiang Province). The ecological habitat information on all the strains except 7 diatoms was shown in Fig. 3 and supplementary data, including the geographical location, water temperatures and $\mathrm{pH}$ value.

Although 246 and 84 water samples were collected from Zhejiang and Jilin, 41 and 7 diatom strains were obtained from these samples respectively. Only 24 from the former and 19 from the latter were collected at temperatures lower than $25^{\circ} \mathrm{C}$ with the highest record of 38 and $28^{\circ} \mathrm{C}$, respectively. However, 20, 12, and 11 diatom strains were obtained from 58, 50, and 51 water samples collected from Liaoning, Heilongjiang and Inner Mongolia, whose average temperatures were around $20^{\circ} \mathrm{C}$. In particular, the lowest temperature was $11^{\circ} \mathrm{C}$ in Liaoning, $19^{\circ} \mathrm{C}$ in Inner Mongolia, and $20^{\circ} \mathrm{C}$ in Heilongiiang. It is indicated that diatoms have a preference for low 


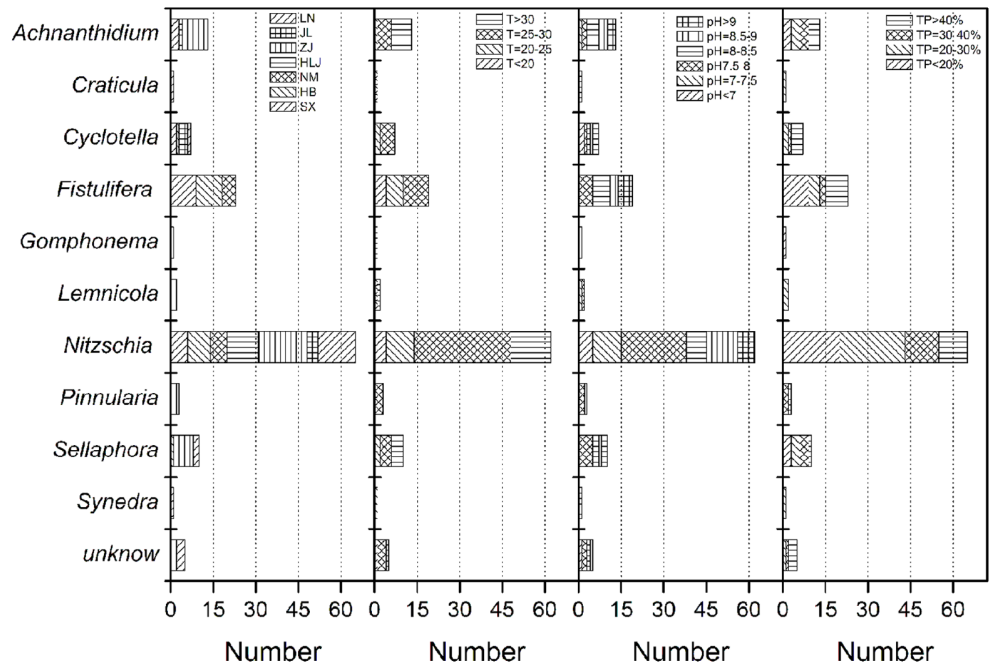

Fig. 3. Summary of uni-algal culture of diatoms isolated from different regions in China (LN: Liaoning Province; JL: Jilin Province; ZJ: Zhejiang Province; HLJ: Heilongjiang Province; NM: Inner Mongolia Autonomous region; HB: Hebei Province; SX: Shanxi Province). T and $\mathrm{pH}$ represent the water temperature $\left({ }^{\circ} \mathrm{C}\right)$ and $\mathrm{pH}$ value of the isolated sites; TP: total lipid content.

temperatures and thus thrive in cold waters $[27,31]$. In this study, $77 \%$ of isolated diatom strains were from waters at temperatures lower than $30^{\circ} \mathrm{C}$, while $23 \%$ of strains were isolated at above $30^{\circ} \mathrm{C}$. It is obvious that many potential high temperature adaptation diatoms can be obtained in summer.

Most of the isolated diatoms (114 strains) prefer alkaline waters, and only 7 strains, including 2 Cyclotella strains and 5 Nitzschia strains, were isolated from acidic waters. This indicates that most of the diatoms possess efficient $\mathrm{CO}_{2}$ concentrating mechanisms (CCMs), and are able to assimilate bicarbonate directly or via extracellular

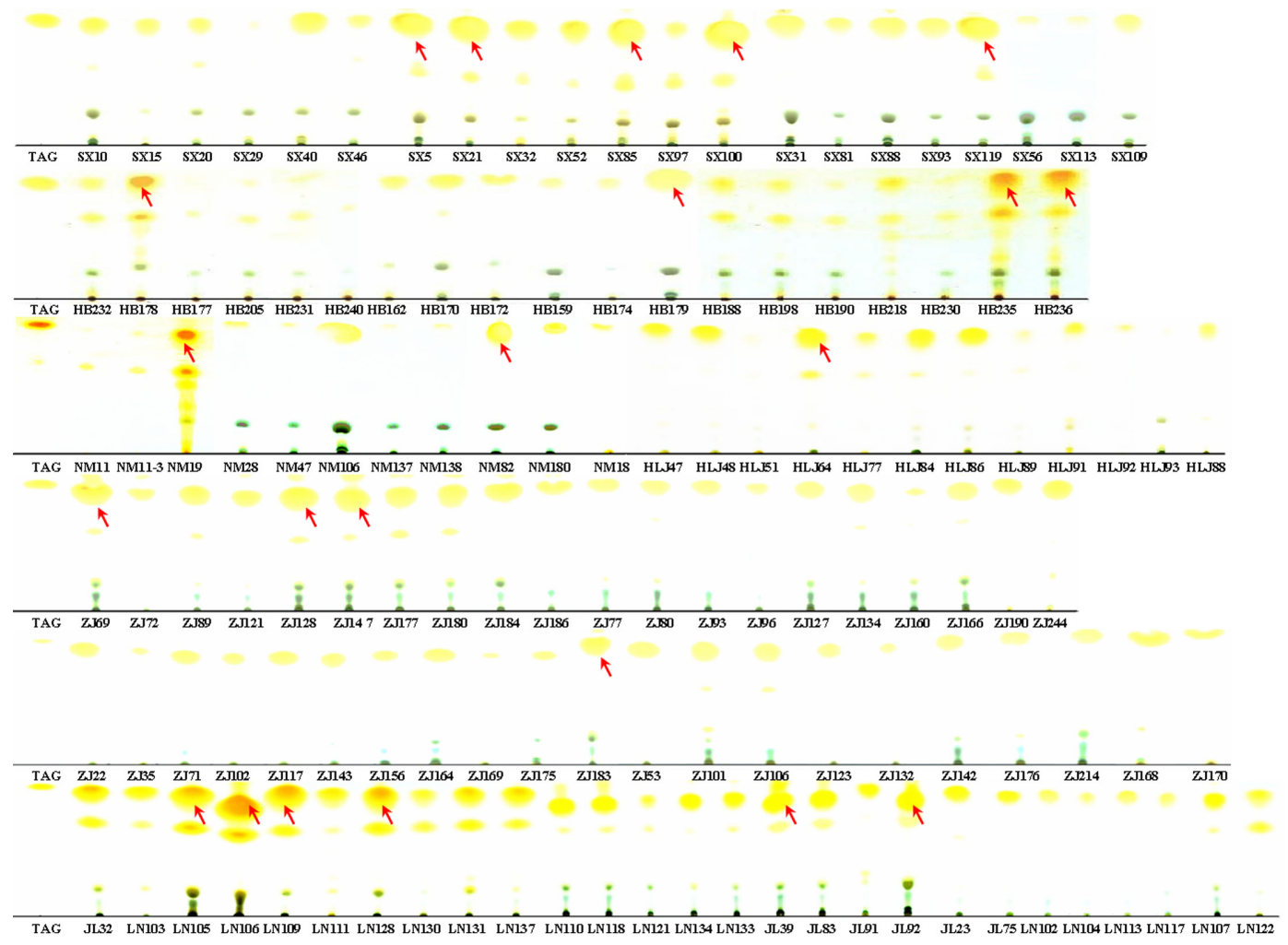

Fig. 4. Comparison of triacylglycerol (TAG) contents in diatoms isolated from different regions in China by TLC (TAG: $0.02 \mathrm{mg}$ triolein). Strains with relatively high TAG content are indicated by arrows. 
carbonic anhydrases [32]. Strains of Nitzschia accounted for a significant proportion (over 50\%) in the isolated diatoms, indicating a wide distribution in freshwater habitats. Among them, 19 strains belong to $N$. palea, which was present in water samples of all the 7 regions. N. palea has been found to be a widely distributed freshwater diatom in various lotic and lentic habitats [33]. About half of the isolated Nitzschia strains inhabited water with a temperature range from 25 to $30^{\circ} \mathrm{C}$ and $\mathrm{pH}$ range from 7.5 to 8.5 .

More than $40 \%$ of the isolated diatom strains boasted a total lipid content of over $30 \%$, suggesting diatoms are a good candidate for lipid production. Diatoms mainly store carbon and energy in the form of lipids, especially under stress [14]. The lipid content in 21\% of the isolated Nitzschia and Fistulifera strains amounted to over 40\%, which makes our screening for high oleaginous diatoms possible.

TAGs, which can be converted via a transesterification process, are believed to be superior to other lipids for biodiesel production [34]. In this study, total lipids from the 131 isolated diatom strains were tested preliminarily by TLC for their TAG contents (Fig. 4). According to the images of TLC (Fig. 4), a band corresponding to standard triolein was clearly visible in all samples. Therefore, all isolated diatoms contained TAG though the contents were widely different. Based on the gray intensity of TLC images, 5 strains (Fistulifera sp. SX5, Fistulifera sp. SX100, Nitzschia sp. SX21, Cyclotella sp. SX119 and Achnanthidium sp. SX85) from Shanxi, 4 strains (Fistulifera sp. HB179, Fistulifera sp. HB236, Nitzschia sp. HB178 and Nitzschia sp. HB235) from Hebei, 2 strains (Fistulifera sp. NM19 and Fistulifera sp. NM82) from Inner Mongolia, one strain (Nitzschia sp. HLJ64) from Heilongjiang, 4 strains (Sellaphora sp. ZJ69, Sellaphora sp. ZJ147, Achnanthidium sp. ZJ128 and Nitzschia sp. ZJ183) from Zhejiang, 2 strains (Nitzschia sp. JL39 and Cyclotella sp. JL92) from Jilin, 4 strains (Nitzschia sp. LN109, Nitzschia sp. LN128, and unidentified strains LN105 and LN106) from Liaoning showed relatively higher TAG contents. Especially, strains HB235, HB 236, NM19, ZJ69 and LN106 had rather high TAG contents.

\section{Screening of High Temperature-Tolerant Diatoms}

After preliminary experiments, a total of 49 isolated diatom strains could survive at $30^{\circ} \mathrm{C}$, and they were designated as high temperature-tolerant diatoms. The 49 strains included 26 Nitzschia, 9 Fistulifera, 6 Sellaphora, 3 Achnanthidium, 1 Cyclotella and 3 unknown species. Twenty-nine strains out of the 49 high temperature-tolerant ones were isolated from waters at above $25^{\circ} \mathrm{C}$, and among them 7 were from waters at above $30^{\circ} \mathrm{C}$. Although diatoms prefer low temperatures, screening diatom strains with high temperature tolerance in hot seasons is also feasible. For example, Nitzschia sp. ZJ183 and Nitzschia sp. ZJ184 were isolated at around $30^{\circ} \mathrm{C}$, and Cyclotella sp. HB162, N. palea HB170 and Fistulifera sp. HB236 were from waters of $23-26^{\circ} \mathrm{C}$. However, Nitzschia sp. HLJ48 was isolated from waters below $20^{\circ} \mathrm{C}$, and it could also survive at $30^{\circ} \mathrm{C}$.

Growth and lipid yields of the 49 high temperature-tolerant diatoms were compared at $28^{\circ} \mathrm{C}$ (Fig. 5). Strains from genus Nitzschia (including HB170, HLJ48 and ZJ183) showed higher relative cell biomass, while Fistulifera sp. HB236 and Nitzschia sp. JL83 had the highest total lipid content in all the 49 diatoms except for the two unidentified strains LN105 and LN106. Genera Achnanthidium, Craticula and Sellaphora showed much lower lipid yields compared with the others. In contrast, thirteen Nitzschia strains showed much higher relative lipid

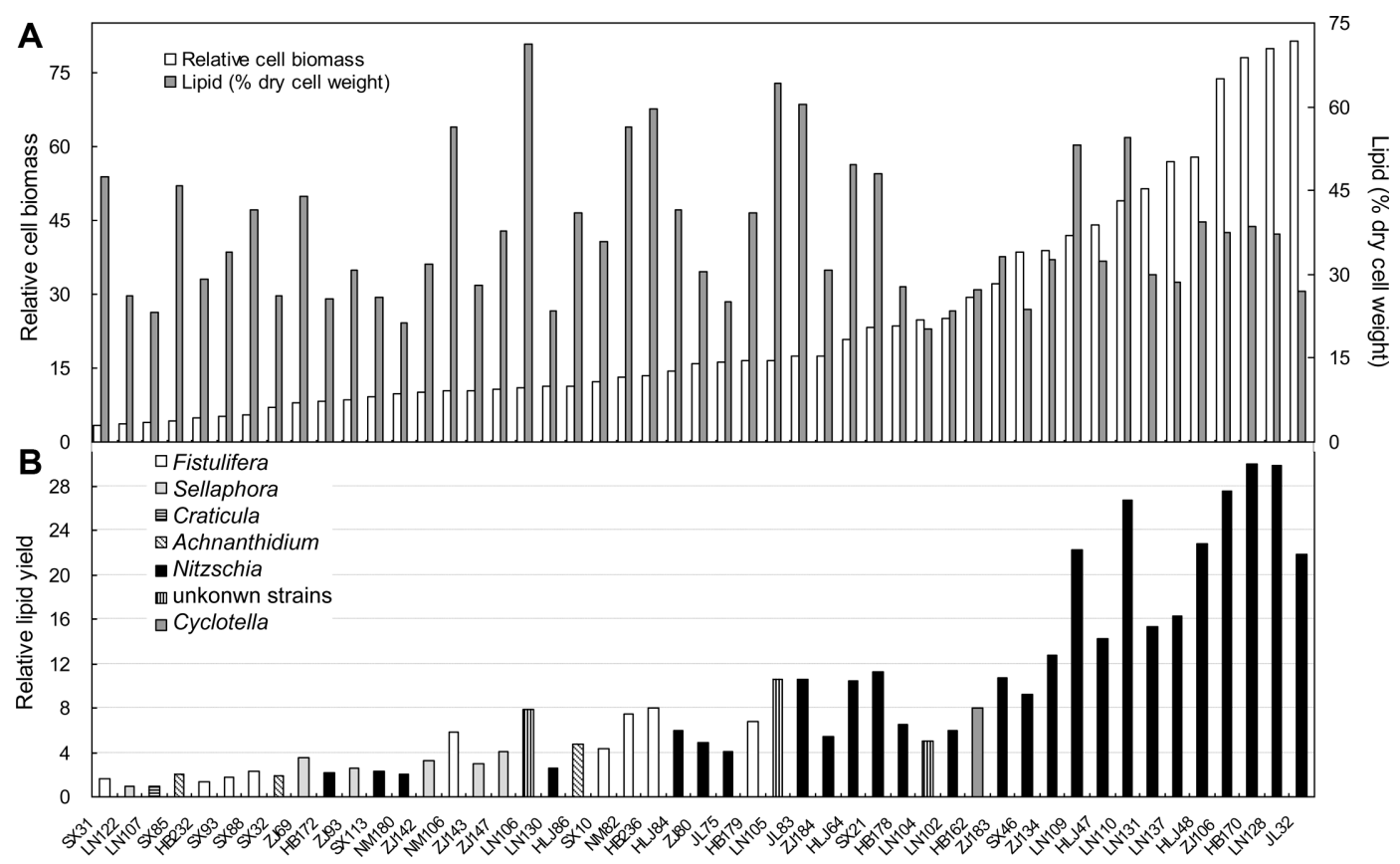

Fig. 5. Relative cell biomass, lipid content (A) and relative lipid yield (B) of high-temperature-tolerant diatoms grown at $28^{\circ} \mathrm{C}$ for 10 days. Relative cell biomass was calculated based on the cell density and cell area, and relative lipid yield was calculated based on the relative cell biomass and lipid content. 
yields, and strain HB170 had the highest relative lipid yield. HB236 had the highest lipid yield in all 9 high temperature-tolerant Fistulifera strains, and HB162 was the only high temperature-tolerant strain of genus Cyclotella. Nitzschia sp. ZJ184 had a relative low lipid yield among all the high temperature-tolerant Nitzschia strains, and was used as a control in this study. Therefore, Fistulifera sp. HB236, Cyclotella sp. HB162 and four Nitzschia strains (HB170, HLJ48, ZJ183 and ZJ184) were selected for further detailed research.

\section{Temperature Adaptability of 6 Representative Diatom Strains}

Six selected diatoms were cultivated at temperatures ranging from 22 to $40^{\circ} \mathrm{C}$ to observe their response to temperatures (Fig. 6). All strains could grow at temperatures from 22 to $35^{\circ} \mathrm{C}$, but were incapable of normal growth at $40^{\circ} \mathrm{C}$. It was reported that temperatures higher than $35^{\circ} \mathrm{C}$ are usually lethal for a number of species [35]. Fistulifera sp. HB236 and 4 Nitzschia strains not only grew best but also showed the highest lipid content at $25^{\circ} \mathrm{C}$, however the optimum growth temperature of Cyclotella sp. HB162 was $28^{\circ} \mathrm{C}$, though its lipid content was sharply decreased at that temperature (Fig. 7). Cyclotella meneghiniana has optimum growth at $25^{\circ} \mathrm{C}$, and an obvious decrease occurred at $30^{\circ} \mathrm{C}$ [36]. The highest cell density of $42.46 \times 10^{4}$ cells $/ \mathrm{ml}$ was achieved in Cyclotella sp. FACHB-1677 with a specific growth rate of $0.188 \mathrm{~d}^{-1}$ at $30^{\circ} \mathrm{C}$ [37]. Although its cell density is comparable to that in Cyclotella sp. HB162 in our study, its specific growth rate is much lower. Jiang et al. [38] revealed that the optimal season for Nitzschia sp. to produce biomass was summer $\left(23-37^{\circ} \mathrm{C}\right)$ but the best lipid production occurred in winter $\left(2-17^{\circ} \mathrm{C}\right)$. Fistulifera solaris was well adapted to high-temperature environments, and even in summer when average daily ambient temperature exceeded $30^{\circ} \mathrm{C}$ and temporarily reached $42^{\circ} \mathrm{C}$, steady biomass $(0.31$ $0.57 \mathrm{~g} / \mathrm{l})$ and lipid content (18\%) of the microalgae were observed under outdoor mass cultivation [39]. In this study, a dramatic decrease in cell density was observed when the 6 strains were cultivated at $35^{\circ} \mathrm{C}$, but the specific growth rates of most of these diatoms at $35^{\circ} \mathrm{C}$ are comparable with those at $32^{\circ} \mathrm{C}$. In particular, N. palea $\mathrm{HB} 170$ and
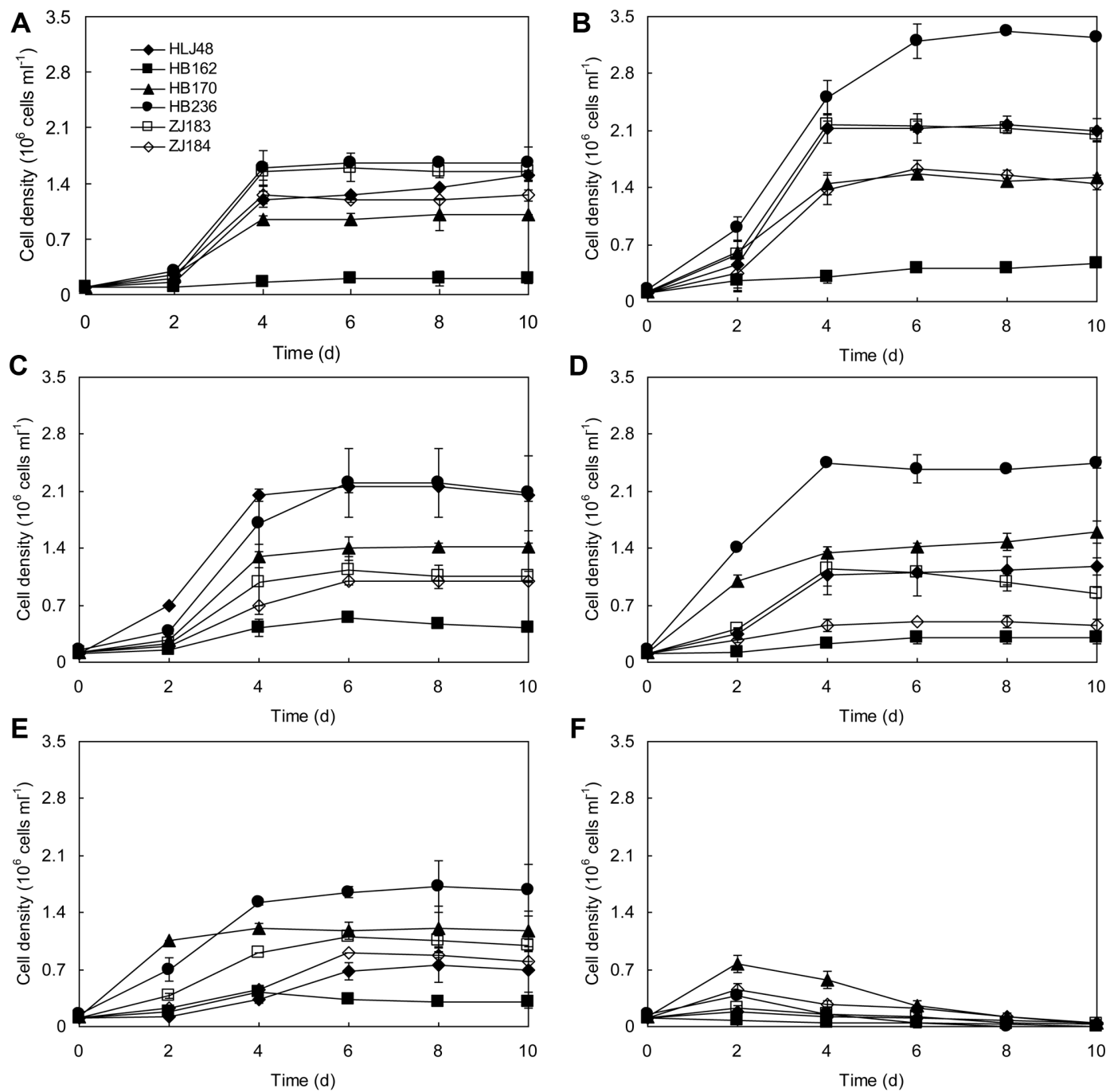

Fig. 6. Growth curves of six representative diatoms at different temperatures $\left(A: 22^{\circ} \mathrm{C} ; \mathrm{B}: 25^{\circ} \mathrm{C} ; \mathrm{C}: 28^{\circ} \mathrm{C} ; \mathrm{D}\right.$ : $\left.32^{\circ} \mathrm{C} ; \mathrm{E}: 35^{\circ} \mathrm{C} ; \mathrm{F}: 40^{\circ} \mathrm{C}\right)$. 

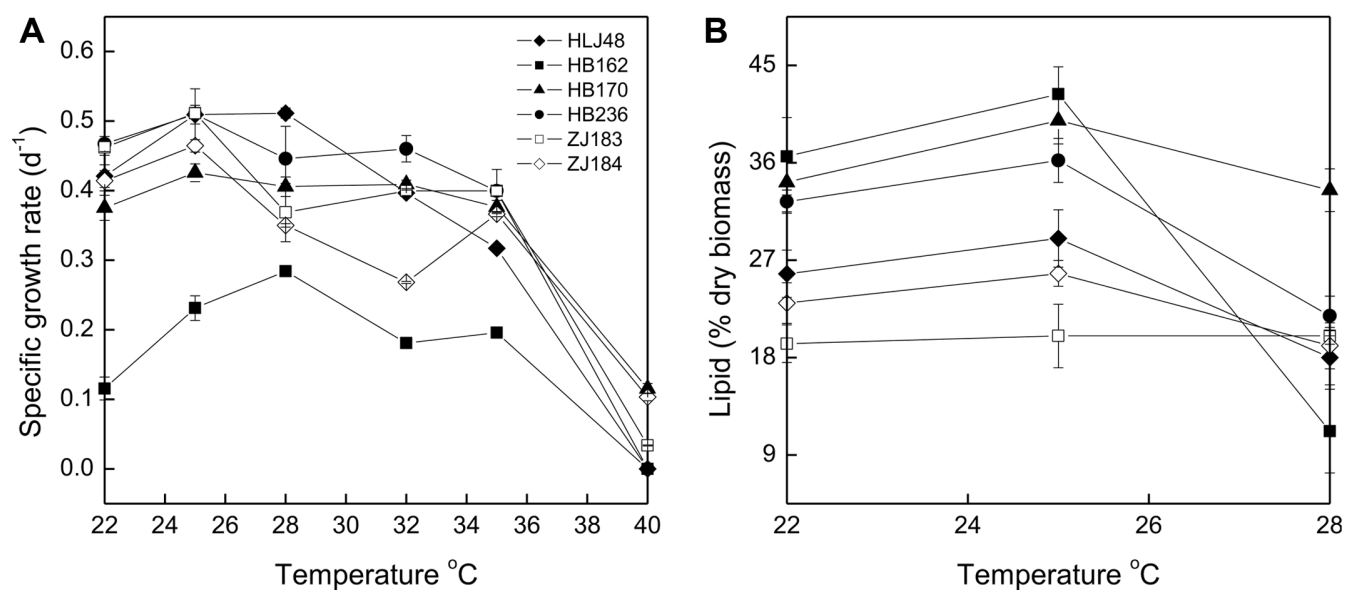

Fig. 7. Specific growth rates (A) and total lipid contents (B) of six representative diatoms at different temperatures.

Fistulifera sp. HB236 presented a small variation of specific growth rates within the scope of $28 \sim 35^{\circ} \mathrm{C}$, thus having excellent temperature adaptability.

\section{Lipid Yields and Fatty Acid Compositions of 6 Representative Diatom Strains}

Fig. 8 showed the dry biomass and TAG contents of 6 diatom strains grown at $25^{\circ} \mathrm{C}$ for 10 days. Although its cell density was the lowest, Cyclotella sp. HB162 had the highest dry biomass of $0.46 \mathrm{~g} / \mathrm{l}$ and relatively high TAG content of $237.4 \mathrm{mg} / \mathrm{g}$ dry biomass. The highest TAG content of $246.4 \mathrm{mg} / \mathrm{g}$ dry biomass was obtained in Fistulifera sp. HB236. The cell sizes (areas) of HB162 were the biggest $\left(235 \pm 18 \mu \mathrm{m}^{2}\right)$ among all high temperature-tolerant diatoms, and were as much as 7 times bigger than that in strain ZJ183 $\left(28 \pm 2 \mu \mathrm{m}^{2}\right)$. Cell sizes (areas) of strains HLJ48, HB236 and ZJ184 were $34 \pm 3,36 \pm 6$, and $39 \pm 3 \mu \mathrm{m}^{2}$, and that of strain HB170 was $84 \pm 8 \mu \mathrm{m}^{2}$. Thus, the dry biomass at day 10 was much lower in strains ZJ183 (0.12 g/l), ZJ184 (0.17 g/l), and HLJ48 (0.19 g/l). Since the highest cell density was observed in strain $\mathrm{HB} 236$ at $25^{\circ} \mathrm{C}$, the relatively high dry biomass $(0.28 \mathrm{~g} / \mathrm{l})$ was also obtained in this strain. N. palea HB170 had high dry biomass $(0.33 \mathrm{~g} / \mathrm{l})$ but relatively low TAG content $(105.9 \mathrm{mg} / \mathrm{g}$ dry biomass). TAG contents in strains ZJ183, ZJ184 and HLJ48 were 70.7, 95.5, and $135.9 \mathrm{mg} / \mathrm{g}$ dry biomass. Therefore, the highest TAG yield of $109.4 \mathrm{mg} / \mathrm{l}$ was obtained in strain $\mathrm{HB} 162$ and the lowest of $8.3 \mathrm{mg} / \mathrm{l}$ in strain ZJ183.

Besides high lipid content, an adequate fatty acid profile is indispensable in microalgae as a renewable feedstock for biodiesel production $[18,19]$. The fatty acid composition of 6 diatom strains possessed a classical characteristic of class bacillariophyceae, which was mainly composed of C14:0, C16:0, C16:1, C18:0, and C20:5 (Table 1). These main fatty acids accounted for $86-97 \%$ of total fatty acids in both total lipids and TAGs. The percentages of SAFA and MUFA in the 6 strains were $84-91 \%$ in total lipids and $90-94 \%$ in TAGs, respectively. Accordingly, polyunsaturated fatty acid (PUFA) content was lower than 10\% in TAGs of all 6 selected diatom strains, which makes these diatoms the ideal feedstock for biodiesel according to the requirements of the European Standard EN 14214 [40]. In particular, HB162 had rather high SAFA and MUFA percentages in both total lipids (90\%) and

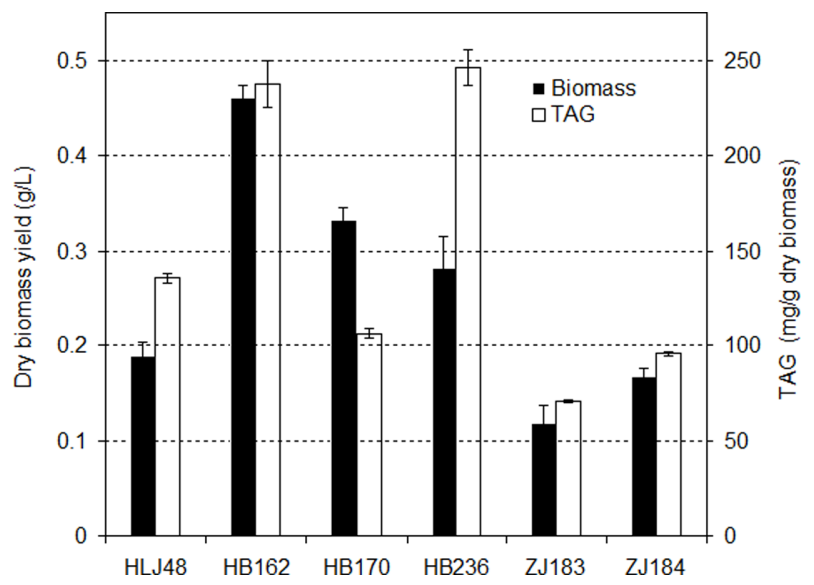

Fig. 8. The dry biomass and TAG contents of six representative diatoms grown under optimal temperature conditions. 
Table 1. Fatty acid (FA) compositions (\% of total fatty acids) of total lipids and triacylglycerols (TAGs) in six diatoms.

\begin{tabular}{|c|c|c|c|c|c|c|c|c|c|c|c|c|}
\hline \multirow{2}{*}{ FA } & \multicolumn{2}{|c|}{ HLJ48 } & \multicolumn{2}{|c|}{ HB162 } & \multicolumn{2}{|c|}{ HB170 } & \multicolumn{2}{|c|}{ HB236 } & \multicolumn{2}{|c|}{ ZJ183 } & \multicolumn{2}{|c|}{ ZJ184 } \\
\hline & Total lipids & TAGs & Total lipids & TAGs & Total lipids & TAGs & Total lipids & TAGs & Total lipids & TAGs & Total lipids & TAGs \\
\hline 14:0 & $9.52 \pm 0.15$ & $.37 \pm 0.55$ & $12.8 \pm 0$ & $18.15 \pm 0.21$ & $11.17 \pm 0.52$ & $12.99 \pm 0.68$ & $11.72 \pm 0.17$ & $7.08 \pm 0.02$ & $7.7 \pm 0.27$ & $7.17 \pm 0.04$ & $8.81 \pm 0.05$ & $9.53 \pm 0.21$ \\
\hline C14:1 & $2.21 \pm 0.38$ & $0.44 \pm 0.32$ & $1.94 \pm 0.11$ & $0.38 \pm 0.2$ & $3.34 \pm 0.56$ & $0.18 \pm 0.09$ & $0.65 \pm 0.05$ & $0.66 \pm 0.06$ & $1.26 \pm 0.07$ & $1.04 \pm 0.05$ & $0.45 \pm 0.15$ & $0 \pm 0$ \\
\hline C16:0 & $34.05 \pm 0.79$ & $39.54 \pm 1.69$ & $26.65 \pm 0.75$ & $30.07 \pm 0.7$ & $28.87 \pm 0.27$ & $30.36 \pm 1.26$ & $32.99 \pm 0.37$ & $34.99 \pm 0.01$ & $38.26 \pm 0.29$ & $41.92 \pm 0.99$ & $28.66 \pm 0.67$ & $35.74 \pm 0.43$ \\
\hline $16: 1$ & $34.51 \pm 0.46$ & $34.15 \pm 0.5$ & $34.59 \pm 0.57$ & $41.58 \pm 0.57$ & $37.38 \pm 0.09$ & $44.77 \pm 0.4$ & $35.07 \pm 0.52$ & $41.67 \pm 0.5$ & $34.49 \pm 0.44$ & $33.19 \pm 0.35$ & $5 \pm 0.4$ & $41.05 \pm 0.04$ \\
\hline C18:0 & $6.29 \pm 0.01$ & $5.99 \pm 1.14$ & $12.29 \pm 0.25$ & $1.76 \pm 0.17$ & $1.64 \pm 0.04$ & $1.61 \pm 0.6$ & $4.05 \pm 0.66$ & $2.91 \pm 0.08$ & $8.37 \pm 0.59$ & $6.75 \pm 0.41$ & $10.07 \pm 0.32$ & $4.45 \pm 0.19$ \\
\hline C18:1 & $1.2 \pm 0.12$ & $3.65 \pm 0.17$ & $1.35 \pm 0.68$ & $0.16 \pm 0.07$ & $0.76 \pm 0.03$ & $0.99 \pm 0.15$ & $0.45 \pm 0.01$ & $2.6 \pm 0.48$ & $0.55 \pm 0.03$ & $0.67 \pm 0.07$ & $0.86 \pm 0.26$ & $2.47 \pm 0.02$ \\
\hline C18:2 & $0.87 \pm 0.66$ & $3.57 \pm 0.94$ & $0.14 \pm 0.17$ & $0.99 \pm 0.02$ & $1.5 \pm 0.02$ & $1.23 \pm 0.33$ & $0.18 \pm 0.02$ & $1.57 \pm 0.32$ & $0.45 \pm 0.01$ & $0.69 \pm 0.02$ & $0.47 \pm 0.12$ & $1.48 \pm 0.04$ \\
\hline C18:3 & $0.65 \pm 0.2$ & $0.34 \pm 0.19$ & $0.49 \pm 0.04$ & $0.83 \pm 0.15$ & $3.08 \pm 0.33$ & $1.83 \pm 0.08$ & $0.77 \pm 0.03$ & $0.63 \pm 0.12$ & $0.57 \pm 0.01$ & $1.03 \pm 0.19$ & \pm 0.5 & $3.25 \pm 0.01$ \\
\hline C18:4 & $0.19 \pm 0$ & $0.31 \pm 0.01$ & $0.78 \pm 0.08$ & $0.82 \pm 0.05$ & $0.32 \pm 0.45$ & $0.93 \pm 0$ & $0.2 \pm 0.01$ & $0.4 \pm 0.03$ & $0.32 \pm 0$ & $0.34 \pm 0.07$ & $0.9 \pm 0.06$ & $0 \pm 0$ \\
\hline $\mathrm{C} 20: 0$ & $0.06 \pm 0$ & $0.25 \pm 0.04$ & $0.1 \pm 0$ & $0.32 \pm 0.05$ & $0.66 \pm 0.94$ & $0.02 \pm 0.02$ & $0.11 \pm 0$ & $0.3 \pm 0.17$ & $0 \pm 0$ & $0.19 \pm 0.01$ & $0 \pm 0$ & $0.8 \pm 0.11$ \\
\hline C20:4 & $0.94 \pm 0.02$ & $0.75 \pm 0$ & $0.04 \pm 0.03$ & $0 \pm 0$ & $1.55 \pm 0.07$ & $0.98 \pm 0$ & $1.11 \pm 0.03$ & $0.72 \pm 0.05$ & $0.8 \pm 0.03$ & $1.22 \pm 0.11$ & $0.84 \pm 0.08$ & $0.23 \pm 0.2$ \\
\hline C20:5 & $9.19 \pm 0.55$ & $4.61 \pm 0.74$ & $8.64 \pm 0.07$ & $.93 \pm 0.65$ & $7.33 \pm 0.17$ & $4.11 \pm 0.08$ & $12.7 \pm 0.02$ & $6.39 \pm 0.21$ & $7.23 \pm 0.19$ & $5.8 \pm 0.01$ & $11.86 \pm 0.19$ & $0.89 \pm 0.01$ \\
\hline $\mathrm{C} 22: 5$ & $0.31 \pm 0.08$ & $0.04 \pm 0.05$ & $0.19 \pm 0.03$ & $0 \pm 0$ & $2.39 \pm 0.01$ & $0 \pm 0$ & $0 \pm 0$ & $0.07 \pm 0.10$ & $0 \pm 0$ & $0 \pm 0$ & $0 \pm 0$ & $0.09 \pm 0.07$ \\
\hline SAFA & 49.92 & 52.15 & 51.84 & 50.3 & 42.34 & 44.98 & 48.87 & 45.28 & 54.33 & 56.03 & 47.54 & 50.52 \\
\hline PUFA & 12.15 & 9.62 & 10.28 & 7.57 & 16.17 & 9.08 & 14.96 & 9.78 & 9.37 & 9.08 & 15.48 & 5.94 \\
\hline
\end{tabular}

SAFA: saturated FA; MUFA: monounsaturated FA; PUFA: polyunsaturated FA.

TAGs (92\%). The effects of temperature on the degree of fatty acid saturation in various diatoms have been studied extensively $[16,41-46)$ and lower temperature increased the contents of PUFA. Only a few studies on diatoms of genus Amphora, whose fatty acid profile is different from that of other diatoms, reported that the PUFAs were higher at the higher temperature $[43,47]$. Although the percentage of SAFA and MUFA in our 6 strains was rather high, it is worth investigating the effects of temperature on fatty acid compositions of these strains and optimizing the content and composition of fatty acids.

In conclusion, diatoms store excess photosynthate as lipids instead of carbohydrates, and are recognized as very promising microalgae for biofuel production. However, diatoms have a preference for low temperatures and usually could not survive at high temperatures, making them unsuitable for outdoor cultivation. In this study, 131 diatom strains were isolated from China in summer, and among them, 49 strains could survive at $30^{\circ} \mathrm{C}$. Six screened diatoms with relatively high biomass and lipid content out of the 49 strains could grow at $35^{\circ} \mathrm{C}$, but showed different responses in growth and TAG yield to high temperatures. N. palea HB170 and Fistulifera sp. HB236 presented relatively stable growth rate and TAG yield under fluctuating temperatures ranging from 28 to $35^{\circ} \mathrm{C}$, while Cyclotella $\mathrm{HB} 162$ can be used as an oil source at temperatures below $25^{\circ} \mathrm{C}$. Our results demonstrate that strains HB170 and HB236 are highly desirable candidates for outdoor cultivation, while strain HB162 may be a better choice under a relatively low temperature.

\section{Acknowledgments}

This work was supported by the Featured Institute Service Projects from the Institute of Hydrobiology, the Chinese Academy of Sciences (Grant No. Y85Z061601) and the National Basic Work of Science and Technology of China (2012FY112900).

\section{Conflict of Interest}

The authors have no financial conflicts of interest to declare.

\section{References}

1. Schenk PM, Thomas-Hall SR, Stephens E, Marx UC, Mussgnug JH, Posten C, et al. 2008. Second generation biofuels: high-efficiency microalgae for biodiesel production. BioEnergy Res. 1:20-43.

2. Meng X, Yang J, Xu X, Zhang L, Nie Q, Xian M. 2009. Biodesel production from oleaginous microorganisms. Renew. Energy. 34: 1-5.

3. Mata TM, Martins AA, Caetano NS. 2010. Microalgae for biodiesel production and other applications: a review. Renew. Sust. Energ. Rev. 14: 217-232.

4. Chisti Y. 2019. Introduction to algal fuels, pp. 1-31. In Pandey A, Chang JS, Soccol CR, Lee DJ, Chisti Y (eds.), pp. 603. Biofuels from Algae (2 $2^{\text {nd }}$ Edition). Elsevier, Boston, MA, USA.

5. Borowitzka MA, Moheimani NR. 2013. Sustainable biofuels from algae. Mitig. Adapt. Strat. Gl. 18: 13-25.

6. Rodolfi L, Zittelli GC, Bassi N, Padovani G, Biondi N, Bonini G, et al. 2009. Microalgae for oil: strain selection, induction of lipid synthesis and outdoor mass cultivation in a low-cost photobioreactor. Biotechnol. Bioeng. 102: 100-112.

7. Wijffels RH, Barbosa MJ. 2010. An outlook on microalgal biofuels. Science 329: 796-799.

8. Chen X, He G, Deng Z, Wang N, Jiang W, Chen S. 2014. Screening of microalgae for biodiesel feedstock. Adv. Microbiol. 4: 365-376.

9. Gao C, Zhai Y, Ding Y, Wu Q. 2010. Application of sweet sorghum for biodiesel production by heterotrophic microalga Chlorella protothecoides. Appl. Energy 87: 756-761.

10. Lam MK, Lee KT. 2012. Potential of using organic fertilizer to cultivate Chlorella vulgaris for biodiesel production. Appl. Energy 94 : 303-308.

11. Vooren GV, Grand FL, Legrand J, Cuiné S, Peltiere G, Pruvost J. 2012. Investigation of fatty acids accumulation in Nannochloropsis oculata for biodiesel application. Bioresour. Technol. 124: 421-432. 
12. Traller JC, Cokus SJ, Lopez DA, Gaidarenko O, Smith SR, McCrow JP, et al. 2016. Genome and methylome of the oleaginous diatom Cyclotella cryptica reveal genetic flexibility toward a high lipid phenotype. Biotechnol. Biofuels 9: 258.

13. Yu S-J, Shen X-F, Ge H-Q, Zheng H, Chu F-F, Hu H, et al. 2016. Role of sufficient phosphorus in biodiesel production from diatom Phaeodactylum tricornutum. Appl. Microbiol. Biotechnol. 100: 6927-6934.

14. Hildebrand M, Davis AK, Smith SR, Traller JC, Abbriano R. 2012. The place of diatoms in the biofuels industry. Biofuels 3: 221-240.

15. Kooistra WHCF, Gersonde R, Medlin LK, Mann DG. 2007. The origin and evolution of the diatoms: their adaptation to a planktonic existence, pp. 207-249. In Falkowski PG, Knoll AH (eds.), Evolution of primary producers in the sea. Elsevier, Boston, MA, USA.

16. Rousch JM, Bingham SE, Sommerfeld MR. 2003. Changes in fatty acid profiles of thermo-intolerant and thermo-tolerant marine diatoms during temperature stress. J. Exp. Mar. Biol. Ecol. 295: 145-156.

17. $\mathrm{Hu} \mathrm{H}$, Gao K. 2006. Response of growth and fatty acid compositions of Nannochloropsis sp. to environmental factors under elevated $\mathrm{CO}_{2}$ concentration. Biotechnol. Lett. 28: 987-992.

18. Islam MA, Magnusson M, Brown RJ, Ayoko GA, Nabi MN, Heimann K. 2013. Microalgal species selection for biodiesel production based on fuel properties derived from fatty acid profiles. Energies 6: 5676-5702.

19. Singh DK, Mallick N. 2014. Accumulation potential of lipids and analysis of fatty acid profile of few microalgal species for biodiesel feedstock. J. Microbiol Biotechnol. Res. 4: 37-44.

20. Lebeau T, Robert JM. 2003. Diatom cultivation and biotechnologically relevant products. Part I: cultivation at various scales. Appl. Microbiol. Biotechnol. 60: 612-623.

21. Xu J, Hu H. 2013. Screening high oleaginous Chlorella strains from different climate zones. Bioresour. Technol. 144: 637-643.

22. Otsuki A, Watanabe M M, Sugahara K. 1987. Chlorophyll pigments in methanol extracts from ten axenic cultured diatoms and three green algae as determined by reverse phase HPLC with fluorometric detection. J. Phycol. 23: 406-414.

23. $\mathrm{Hu} \mathrm{H}, \mathrm{Li} \mathrm{H}, \mathrm{Xu}$ X. 2008. Alternative cold response modes in Chlorella (Chlorophyta, Trebouxiophyceae) from Antarctica. Phycologia 47: 28-34.

24. Swofford DL. 1998. PAUP* 4.0-phylogenetic analysis using parsimony ( ${ }^{\star}$ and other methods). pp. 604. Sinauer Associates, Sunderland.

25. Reiser S, Somerville C. 1997. Isolation of mutants of Acinetobacter calcoaceticus deficient in wax ester synthesis and complementation of one mutation with a gene encoding a fatty acyl-coenzyme a reductase. J. Bacteriol. 179: 2969-2975.

26. Bligh EG, Dyer WJ. 1959. A rapid method of lipid extraction and purification. Can. J. Biochem. Physiol. 37: 911-917.

27. Willén E. 1991. Planktonic diatoms - an ecological review. Algol. Stud. 62: 69-106.

28. Lundholm N, Daugbjerg N, Moestrup Ø. 2002. Phylogeny of the Bacillariaceae with emphasis on the genus Pseudo-nitzschia (Bacillariophyceae) based on partial LSU rDNA. Eur. J. Phycol. 37: 115-134.

29. Hasle G R. 1994. Pseudo-Nitzschia as a genus distinct from Nitzschia (Bacillariophyceae). J. Phycol. 30: 1036-1039.

30. Tanaka T, Maeda Y, Veluchamy A, Tanaka M, Abida H, Maréchal E, et al. 2015. Oil accumulation by the oleaginous diatom Fistulifera solaris as revealed by the genome and transcriptome. Plant Cell 27: 162-176.

31. Potapova MG, Charles DF. 2002. Benthic diatoms in USA rivers: distributions along spatial and environmental gradients. J. Biogeogr. 29: 167-187.

32. Clement R, Jensen E, Prioretti L, Maberly SC, Gontero B. 2017. Diversity of $\mathrm{CO}_{2}$-concentrating mechanisms and responses to $\mathrm{CO}_{2}$ concentration in marine and freshwater diatoms. J. Exp. Bot. 68: 3925-3935.

33. Trobajo R, Clavero E, Chepurnov VA, Sabbe K, Mann DG, Ishihara S, et al. 2009. Morphological, genetic and mating diversity within the widespread bioindicator Nitzschia palea (Bacillariophyceae). Phycologia 48: 443-459.

34. Hu Q, Sommerfeld M, Jarvis E, Ghirardi M, Posewitz M, Seibert M, et al. 2008. Microalgael triacylglycerols as feedstocks for biofuel production: perspectives and advances. Plant J. 54: 621-639.

35. Lavens P, Sorgeloos P. 1996. Manual on the production and use of live food for aquaculture. pp. 295. FAO Fisheries Technical Paper, Rome.

36. Shafik HM, Herodek S, Vörös L, Présing M, Kiss KT. 1997. Growth of Cyclotella meneghiniana Kutz. I. Effects of temperature, light and low rate of nutrient supply. Ann. Limnol.-Int. J. Lim. 33: 139-147.

37. Li X, Marella TK, Tao L, Li R, Tiwari A, Li Gu. 2017. Optimization of growth conditions and fatty acid analysis for three freshwater diatom isolates. Phycol. Res. 65: 177-187.

38. Jiang Y, Laverty KS, Brown J, Nunez M, Brown L, Chagoya J, et al. 2014. Effects of fluctuating temperature and silicate supply on the growth, biochemical composition and lipid accumulation of Nitzschia sp. Bioresour. Technol. 154: 336-344.

39. Sato R, Maeda Y, Yoshino T, Tanaka T, Matsumoto M. 2014. Seasonal variation of biomass and oil production of the oleaginous diatom Fistulifera sp. in outdoor vertical bubble column and raceway-type bioreactors. J. Biosci. Bioeng. 117: 720-724.

40. European Standard EN. 2004. Automotive fuels-fatty acid methyl esters (FAME) for diesel engines-requirements and test methods. pp. 28. AFNOR, Saint-Denis.

41. Renaud S, Zhou H, Parry D, Thinh L-V, Woo K. 1995. Effect of temperature on the growth, total lipid content and fatty acid composition of recently isolated tropical microalgae Isochrysis sp., Nitzschia closterium, Nitzschia paleacea, and commercial species Isochrysis sp. (clone T. ISO). J. Appl. Phycol. 7: 595-602.

42. Jiang H, Gao K. 2004. Effects of lowering temperature during culture on the production of polyunsaturated fatty acids in the marine diatom Phaeodactylum tricornutum (Bacillariophyceae). J. Phycol. 40: 651-654.

43. Teoh M-L, Phang S-M, Chu W-L. 2013. Response of Antarctic, temperate, and tropical microalgae to temperature stress. J. Appl. Phycol. 25: 285-297.

44. Pasquet V, Ulmann L, Mimouni V, Guihéneuf F, Jacquette B, Morant-Manceau A, et al. 2014. Fatty acids profile and temperature in the cultured marine diatom Odontella aurita. J. Appl. Phycol. 26: 2265-2271.

45. Schaub I, Wagner H, Graeve M, Karsten U. 2017. Effects of prolonged darkness and temperature on the lipid metabolism in the benthic diatom Navicula perminuta from the Arctic Adventfjorden, Svalbard. Polar Biol. 40: 1425-1439.

46. Svenning JB, Dalheim L, Eilertsen HC, Vasskog T. 2019. Temperature dependent growth rate, lipid content and fatty acid composition of the marine cold-water diatom Porosira glacialis. Algal Res. 37: 11-16.

47. Indrayani I, Moheimani NR, de Boer K, Bahri PA, Borowitzka MA. 2020. Temperature and salinity effects on growth and fatty acid composition of a halophilic diatom, Amphora sp. MUR258 (Bacillariophyceae). J. Appl. Phycol. 32: 977-987. 